\title{
SPATIAL ANALYSIS OF ALCOHOL-RELATED MORTALITY IN SLOVAKIA
}

\author{
Matúš Kubák1, Beáta Gavurováa, Adam Kulhánek² \\ ${ }^{1}$ Faculty of Economics, Technical University of Košice, Košice, Slovak Republic \\ 2Department of Addictology, First Faculty of Medicine, Charles University and General University Hospital in Prague, Prague, Czech Republic
}

\section{SUMMARY}

Objective: The aim of our study was to investigate the relationship between alcohol-related mortality in Slovak regions, as represented by Nomenclature of Territorial Units for Statistics (NUTS) III level.

Methods: We used data from mortality reports spanning 1996-2017 in the Slovak Republic. Data was provided by the National Health Information Centre in Slovakia. We applied two-dimensional correspondence analysis where the dimensions are regions and selected alcohol-related deaths diagnoses are classified by the International Classification of Diseases.

Results: Analysis revealed a relationship between the Prešov region and diagnoses 142 - Cardiomyopathy and K29 - Alcoholic gastritis. Furthermore, the Banská Bystrica and Žilina regions correspond to G31 - Degeneration of nervous system due to alcohol and K86 - Alcohol-induced chronic pancreatitis. In the case of K70 - Alcoholic liver disease - the Banská Bystrica, Trenčín and Nitra regions are identified as regions which have an intermediate relationship with this diagnosis. The Trnava region corresponds to F10 - Acute alcohol intoxication. The Trenčín and Nitra regions correspond closely to G62 - Alcoholic polyneuropathy. Perfect correspondence can be seen between the Košice region and K73 - Chronic hepatitis, not elsewhere classified. K74 - Fibrosis and cirrhosis of liver diagnosis also corresponds with the Košice region.

Conclusions: The results of this analysis provide valuable insights for national and regional health policymakers in the process of preparing high-quality health regional plans, as well as retrospectively assessing the success of existing health policies and interventions in this area. Facts presented in the study justify the need for specialised health care, which is part of the process of building an Integrated Health Care Centre in Slovakia.

Key words: alcohol-related deaths, correspondence analysis, region, Slovakia

Address for correspondence: B. Gavurová, Department of Addictology, First Faculty of Medicine, Charles University and General University Hospital in Prague, Apolinárská 4, 12800 Prague 2, Czech Republic. E-mail: beata.gavurova@lf1.cuni.cz

https://doi.org/10.21101/cejph.a5766

\section{INTRODUCTION}

The issue of eliminating health inequalities in the regions is one of the key challenges for health policies in EU states. Many socioeconomic and socio-demographic factors affect health inequalities, manifesting themselves in varying degrees of morbidity and mortality (1). Their impacts on the economic and social spheres of a given country are very significant. The health of the population is also determined by health behaviour in which risk factors play a decisive role. Important risk factors include the use of alcohol and other addictive substances, an issue which is addressed by many international and national research teams. Alcohol is the third most common health risk factor in the world and is the most common risk factor in low-income countries (2). It is the main cause of more than 200 diseases and injuries, premature disability, and mortality with less than $10 \%$ of alcohol-dependent patients being treated (3). The net effect of alcohol consumption on health is detrimental, with an estimated $3.8 \%$ of all global deaths and $4.6 \%$ of global disability-adjusted life-years attributable to alcohol (4). Recent significant findings declaring the effects of alcohol and drug use on the population of 195 countries and territories in 21 regions, and within seven super-regions, are reflected by the Global Burden of Disease study (GBD) (5). This study examines the association between disease burden and Socio-Demographic Index (SDI) quintiles. Globally, in 2016 a total of 99.2 million Disability-Adjusted Life Years (DALYs) (95\% UI 88.3-111.2) and $4.2 \%$ of all DALYs (3.7-4.6) were attributable to alcohol use, and 31.8 million DALYs (27.4-36.6) and 1.3\% of all DALYs (1.2-1.5) were attributable to drug use as a risk factor. The burden of disease attributable to alcohol and drug use varied substantially across geographical locations, and much of this burden was due to the effect of substance use on other health outcomes (5). The World Health Organisation (WHO) also examines the health, social, psychological and spiritual dimensions of the effects of alcohol use on individuals. Many methodologies are used for economic quantification (decision models, retrospective and prospective studies, averting behaviour method, utility valuation method, willingness-to-pay approach, consumer market method, contingent valuation method, cost-of-illness method etc.). The economic dimensions of the effects of alcohol use are presented in many international and national research studies. The costs associated with alcohol amount to over $1 \%$ of the gross national product in high-income and middle-income countries, with the costs of social harm constituting a major proportion besides health costs (4). In this context we mention an important study by Zábranský et al. (6) and the most recent iHETA study (7) on the social cost 
of alcohol consumption. Nociar (8-10), Madarasová Gecková and Dankulicová (11), Gavurová et al. (12) and others have published relevant studies in a Slovak context. Their priority was to focus on the use of addictive substances in the younger population, especially pupils and students in higher education. Significant knowledge of the state of the drugs problem is also provided by institutional outputs, e.g. the National Drug Monitoring Centre (13). Few studies have researched regional mortality associations in groups of diagnoses associated with alcohol consumption. These are important not only for the creation of specific prevention programmes but also for the development of regional health policies and for assessing the availability of specialised health care.

Many foreign research studies have examined regional disparities related to alcohol and other drug mortality as well as various socioeconomic factors. The results of these studies are oriented towards making recommendations for policymakers in the health and social systems of the countries involved and open the way for the subsequent examination of new determinants of regional disparities in health. The interconnection of macroeconomic health and socioeconomic indicators with mortality is evident in many studies. For example, Monnat (14) in his study explored and modelled associations between drug-related mortality rates at the district level and the economic, social and health environments using a 2006-2015 US database. The average age-standardised drug-related mortality rate at the district level was 16.6 deaths per 100,000 inhabitants. Significant geographical differences prevailed in the mortality rate. Higher mortality has been reported in districts with greater economic and family problems. Average mortality rates were significantly lower in districts with a higher number of religious institutions, with a higher percentage of migrants and in districts with economies linked to employment in the public sector. Significant demographic differences in mortality have been reported in relation to drug use. Subsequent research plans to focus on exploring the relationship between drug-related mortality and the economic, health and social environment of individuals. Rosicova et al. (15) found that unemployment rates and low education levels are important determinants of regional alcohol-related mortality in Slovakia. Barrios et al. (16) explored the geographical and gender differences in oesophageal cancer mortality related to alcohol consumption and tobacco smoking. Oesophageal cancer incidence data were obtained from 48 cancer registries in 13 countries over a 10-year period. Males had a higher incidence and mortality than females, with the highest rates of oesophageal cancer mortality rates in Brazil, Uruguay, Argentina and Chile in 2003. Geographical differences in oesophageal cancer mortality in Central and South America reflect differences in alcohol use and tobacco smoking. This calls for the implementation of policies to control the use of alcohol and tobacco. Ethnic, gender, regional and age disparities have also been the focus of research by Saint Onge and Krueger (17). Representative US national data was used to target the adult age range of 18 years and older for the period 2004-2009 from the National Health Interview Survey (NHIS). The authors identified 7 distinct groups of health behaviour by examining lifestyle risk factors: alcoholism, smoking, physical inactivity, visits to doctors, vaccination, etc. The authors found significant ethnic, gender, regional and age differences in defined groups of health behaviour which also reflect the lifestyle of the population studied. The authors call for the need to link the results to sociological theories of health behaviour, as well as the need to implement interventions aimed at improving population health. Gennuso et al. (18) examined the risk factors affecting health differences in geographically defined areas. They used 2014 data from the County Health Rankings for districts in 8 states in the Mississippi River area (Alabama, Arkansas, Illinois, Kentucky, Louisiana, Mississippi, Missouri, and Tennessee). They used the Delta Regional Authority definition to identify 252 districts from the Delta area and 468 districts outside these areas. The authors examined 35 indicators in 5 groups: health behaviour, clinical care, social and economic factors, physical environment and demographic variables. The authors found similarities between the Delta districts and districts outside this area in health factors (substance use, nutrition, movement) that significantly affected the results of self-rated health. The results of the study form the basis for the creation of regional health policies aimed at eliminating risk factors and regional disparities in health. Quantifying the regional health differences has also been addressed by Renard et al. (19) who took advantage of the relative scale in the maps, stressing the importance of exploring regional differences between districts in relation to premature deaths. All deaths between 1993 and 1999 and 2003-2009 in the population aged 1 to 74 living in Belgium were included in the analysis. According to the research results, the year-on-year differences in all causes of avoidable mortality increased by 10\% between 1993-1997 and 2003-2009 in both genders. Alcohol-related diagnoses, mental and neurological diseases, and road accidents have also been investigated as part of the diagnosis of avoidable deaths. The results of the analysis also pointed to clear regional health disparities in Wallonia. These disparities are the result of complex interactions between various factors, including socioeconomic context, cultural habits, environmental impacts, as well as public health policies. The results of this study point to great potential for improving health in disadvantaged areas. Jeon et al. (20) investigated the prevalence of hypertension in geographically diverse areas, they compared results from urban and rural areas and were also interested in gender differentiation. Their study used data from the Korea National Health and Nutrition Examination for the period 2010-2012 and a national cross-sectional survey of the South Korean population. In addition to basic demographic indicators, the authors also used risk factors such as alcohol use, smoking, body mass index and economic indicators such as monthly income and educational level. A higher prevalence of hypertension has been found in men in urban areas than in rural areas. Regardless of gender and area, younger people had hypertension and diabetes mellitus under control. Regional disparities between urban and rural areas have been reported in the incidence of hypertension in men. In women, disparities of health status in urban areas were recorded. The results of the study also confirmed the necessity of developing differentiated health policies to address individual and regional health inequalities. The great importance of risk factors in examining regional health differences is discussed by Beard et al. (21). Their study focused on the geographical area of England, the population survey included 53,922 adults aged 16+, who participated in the Alcohol and Smoking Toolkit Studies. High-risk alcohol use has been found in the North of England and to a lesser extent in the Midlands, London and East of England. The analysis shows that regional differences in smoking and less risky drinking are explained to some extent by socio-demographic 
differences. The East European region is characterised by a high prevalence of alcohol use compared to other European countries $(22,23)$. In the case of Slovakia, 16.6 litres per capita reflects more a mid-level of consumption as opposed to 19.1 litres in the Czech Republic (24). Differences between these two geographically and culturally similar countries can be found in the patterns of alcohol use and the proportion of preferred alcoholic drinks. Whereas in Slovakia (24) spirits are the most commonly consumed alcoholic drink (42\%), in the Czech Republic beer consumption is dominant (54\%) and a prevalence of heavy drinking is higher among adult population there (36.2\% vs. $42.1 \%)$. Regarding illicit drugs, methamphetamine use is typically located in Central Europe, especially in the Czech and Slovak Republics (25). The Czech mental health study (CZEMS) (26) have found that the prevalence of alcohol abuse and addiction in the Czech Republic is $11 \%$. Additionally, Kagstrom et al. (27) suggested that the treatment gap for alcohol abuse/addition is the highest among individuals with mental disorders.

Preventive programmes have been the subject of numerous research studies where they are presented either in their explicit form within defined research goals or as output components of research. An interesting look at the concept of prevention processes with implementation of social marketing in alcohol interventions is offered by Janssen et al. (28). The authors investigated the impact of applying social marketing methods on attitudes or behaviour related to alcohol use. In the literature review of PubMed, PsychInfo, Cochrane and Scopus, 274 research studies were investigated. The authors emphasise the importance of social marketing in educational processes related to the elimination of alcohol use and related impacts. Another view of risk and protective family factors associated with alcohol use in children and adults is offered by Čablová and Miovský (29). Their study was aimed at identifying, describing and comparing the results of research on family structure, parental styles, control and setting of rules, family alcohol consumption and emotional warmth and communication. Knowing these determinants and their effects on alcohol use in children and adults will encourage the creation of quality prevention programmes that can prevent the development of alcohol use, especially among youngsters.

The above-mentioned facts prompted us to carry out research with the aim of studying spatial distribution of causes of death which are the direct consequence of excessive alcohol consump- tion in the Slovak Republic. The presented study investigates the relationship between alcohol-induced mortality and individual regions of Slovakia, represented by Nomenclature of Territorial Units for Statistics (NUTS) III level.

\section{MATERIALS AND METHODS}

Our dataset contains data from 1996-2017 and was provided by The National Health Information Centre, a state-funded organisation under the administration of the Ministry of Health of the Slovak Republic. Data are derived from death certificates because for the purposes of this study the place of death and diagnosis are important.

We have focused our analysis on spatial distribution of causes of death which are the direct consequence of excessive use of alcohol. Hence, we were interested in the following diagnoses: F10 - Acute alcohol intoxication, G31 - Degeneration of nervous system due to alcohol, G62 - Alcoholic polyneuropathy, I42 - Cardiomyopathy, K29 - Alcoholic gastritis, K70 - Alcoholic liver disease, K73 Chronic hepatitis, not elsewhere classified, K74 - Fibrosis and cirrhosis of liver and K86 - Alcohol-induced chronic pancreatitis.

For data processing we deployed correspondence analysis (30, 31). Correspondence analysis is a multidimensional visual technique that allows us to graphically display rows and columns of the pivot table and specify the measure of correspondence between the rows and columns. Correspondence analysis is conceptually similar to factor analysis and consists of decomposition of the relative frequencies into main components. Correspondence analysis lets us compute the Euclidean distances between the row points in the $\mathrm{x}$-dimensional space ( $\mathrm{x}$ is the number of columns). The distances between the points in the $\mathrm{x}$-dimensional space summarise all information about the similarities between the rows in the pivot table. Correspondence analysis allows us to determine fewer dimensional spaces, in which it preserves all information about the differences between the rows in the pivot table on a 2-dimensional graph, which is the main output of correspondence analysis. Coordinates in the graph are analogous to factors in a principal component analysis. This method uses nominal variables as inputs. The necessary condition for correspondence analysis use is the existence of the dependence between the observed data.

Data were processed using IBM SPSS ${ }^{\circledR}$ software.

Table 1. Spatial distribution of deaths in 1996-2017

\begin{tabular}{|c|c|c|c|c|c|c|c|c|c|c|}
\hline & \multicolumn{9}{|c|}{ Initial death diagnosis } & \multirow{2}{*}{ Total } \\
\hline & $\mathrm{F} 10$ & G31 & G62 & 142 & K29 & K70 & K73 & K74 & K86 & \\
\hline Bratislava region & 6 & 39 & 7 & 273 & 33 & 1,576 & 61 & 2,063 & 112 & 4,170 \\
\hline Trnava region & 77 & 49 & 3 & 276 & 30 & 1,733 & 69 & 1,364 & 89 & 3,690 \\
\hline Trenčín region & 28 & 50 & 5 & 353 & 62 & 1,417 & 76 & 1,417 & 79 & 3,487 \\
\hline Nitra region & 13 & 71 & 16 & 425 & 42 & 2,425 & 91 & 2,227 & 122 & 5,432 \\
\hline Žilina region & 31 & 85 & 12 & 598 & 56 & 1,657 & 97 & 1,717 & 123 & 4,376 \\
\hline Banská Bystrica region & 11 & 75 & 8 & 642 & 44 & 1,949 & 64 & 1,955 & 145 & 4,893 \\
\hline Prešov region & 8 & 62 & 5 & 680 & 54 & 1,399 & 63 & 1,360 & 106 & 3,737 \\
\hline Košice region & 28 & 80 & 8 & 616 & 47 & 1,651 & 113 & 2,187 & 131 & 4,861 \\
\hline Total & 202 & 511 & 64 & 3,863 & 368 & 13,807 & 634 & 14,290 & 907 & 34,646 \\
\hline
\end{tabular}




\section{RESULTS}

Table 1 depicts the spatial distribution of deaths caused by selected diagnoses from the above-mentioned diagnoses F10, G31, G62, I42, K29, K70, K73, K74, and K86.

Diagnoses pertinent to this study contributed to the total number of deaths over the 22-year observation period by $2.96 \%$ and thus should not be neglected. Table 1 shows that most grievous of the diagnoses are K74 - Fibrosis and cirrhosis of the liver, K70 - Alcoholic liver disease, I42 - Cardiomyopathy and K86 - Alcohol-induced chronic pancreatitis.

Figure 1 depicts the evolution of mortality from the most serious diagnoses related to excessive alcohol use. We can conclude that mortality related to K70 - Alcoholic liver disease has a known serious increase over time. Also, mortality from I42 - Cardiomyopathy has raised over time. On the other hand, we observed a decrease of K74 - Fibrosis, and mortality from cirrhosis of the liver during the observed period. The number of deaths caused by $\mathrm{K} 86$ - Alcohol-induced chronic pancreatitis is also decreasing year by year.

As mentioned above, we were interested in the measure of correspondence between region and selected causes of death which are induced by excessive use of alcohol. In our analysis, we used the chi-square distance measure and symmetrical normalisation

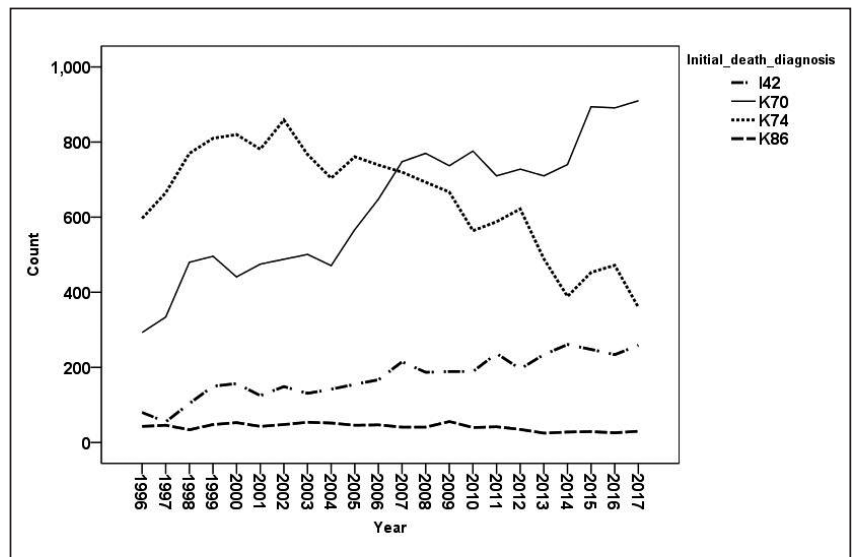

Fig. 1. Evolution of mortality from 142, K70, K74, K86 within period 1996-2017. method. One of the conditions of using the correspondence analysis is the assumption of the existence of dependence between the observed variables. To verify this condition, whether there exists a significant relationship between two nominal variables, we performed Pearson's chi-square test of independence.

H0: There is no significant difference between the observed and the expected value.

H1: There is a significant difference between the observed and the expected value.

According to $\mathrm{p}$-value in chi-square column in Table 2, we rejected the null hypothesis of Pearson's chi-square test of independence and we suppose that there is a dependence between data. Table 2 also shows the proportion of inertia captured by our model.

We can state that our model captures $78.4 \%$ of total inertia. The first dimension contributes $55.8 \%$ of inertia and the second dimension contributes $22.6 \%$, which is in total $78.4 \%$ of inertia. Total inertia is a measure that characterises the quality of the transformation of multidimensional points in the correspondence map. Our model captures $78.9 \%$ of total inertia and thus can be perceived as satisfactory.

Figure 2 contains the results of the correspondence analysis. It should be noted that we weighted our dataset by variable Region since the study was focused on spatial distribution of deaths; this allowed us to assign importance to this variable.

We can see on the correspondence map that we have one outlier in terms of diagnosis, which is F10 - Acute alcohol intoxication, and one outlier in terms of region, which is the Bratislava region. In our opinion, this outlying is caused in case of the Bratislava region mainly because it is economically and socio-demographically under a different regime than other regions in Slovakia. In the case of outlying diagnosis F10 - Acute alcohol intoxication, we suppose that this is due to the nature of the cause of death, which has no latent progress but occurs unexpectedly and accidentally. We see that there is a relationship between the Prešov region and diagnoses I42 - Cardiomyopathy and K29 - Alcoholic gastritis. Furthermore, we can observe a cluster of relatively similar regions which signifies that their chi-square distance is quite small. These regions are Banská Bystrica, Žilina, Trenčín and Nitra regions. In any case, we can also find specificities and differences in this cloud of relatively similar regions. Particularly the Banská Bystrica and Žilina regions are fairly close and both correspond with G31 - Degeneration of nervous system due to alcohol, K86

Table 2. Proportion of inertia

\begin{tabular}{|c|c|c|c|c|c|c|c|c|}
\hline \multirow[b]{2}{*}{ Dimension } & \multirow{2}{*}{$\begin{array}{l}\text { Singular } \\
\text { value }\end{array}$} & \multirow[b]{2}{*}{ Inertia } & \multirow[b]{2}{*}{ Chi square } & \multirow[b]{2}{*}{$\mathrm{p}$-value } & \multicolumn{2}{|c|}{ Proportion of inertia } & \multicolumn{2}{|c|}{ Confidence singular value } \\
\hline & & & & & $\begin{array}{l}\text { Accounted } \\
\text { for }\end{array}$ & Cumulative & $\begin{array}{l}\text { Standard } \\
\text { deviation }\end{array}$ & $\begin{array}{c}\text { Correlation } \\
2\end{array}$ \\
\hline 1 & 0.107 & 0.012 & & & 0.558 & 0.558 & 0.002 & 0.056 \\
\hline 2 & 0.068 & 0.005 & & & 0.226 & 0.784 & 0.003 & \\
\hline 3 & 0.058 & 0.003 & & & 0.163 & 0.948 & & \\
\hline 4 & 0.025 & 0.001 & & & 0.031 & 0.978 & & \\
\hline 5 & 0.018 & 0.000 & & & 0.016 & 0.995 & & \\
\hline 6 & 0.010 & 0.000 & & & 0.005 & 1.000 & & \\
\hline 7 & 0.003 & 0.000 & & & 0.000 & 1.000 & & \\
\hline Total & & 0.021 & $3,313.221$ & $<0.001$ & 1.000 & 1.000 & & \\
\hline
\end{tabular}




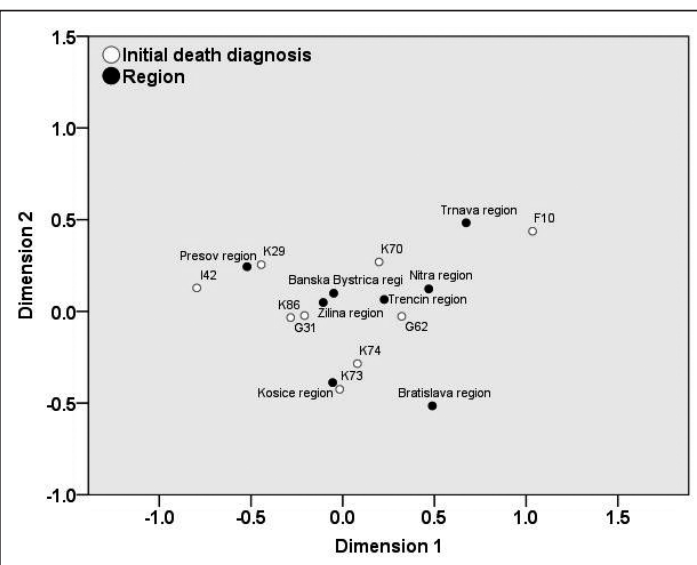

Fig. 2. Correspondence analysis: region/initial death diagnosis.

- Alcohol-induced chronic pancreatitis. An interesting finding concerned diagnosis K70 - Alcoholic liver disease. In this case, three regions can be identified as regions which have an intermediate relationship to this diagnosis: Banská Bystrica, Trenčín and Nitra regions. Trnava is the only region that corresponds to F10 - Acute alcohol intoxication. Next, the Trenčín and Nitra regions correspond relatively closely to G62 - Alcoholic polyneuropathy. We can find almost perfect correspondence between the Košice region and K73 - Chronic hepatitis, not elsewhere classified. Another disease corresponding with the Košice region is K74 Fibrosis and cirrhosis of liver diagnosis.

\section{DISCUSSION}

The aim of this study was to study spatial distribution of causes of death which are the direct consequence of excessive use of alcohol in the Slovak Republic. We present a closer examination of the relationship between alcohol-induced mortality and individual regions of Slovakia, represented by regions (NUTS III level).

The results of our analysis offer interesting findings. Visualisation of results on the correspondence map highlights one outlying diagnosis, which is F10 - Acute alcohol intoxication, and one separately situated region, the Bratislava region. The Prešov region is related to diagnoses I42 - Cardiomyopathy and K29 - Alcoholic gastritis. Of interest is the cluster of similar regions (their chi-square distance is relatively small) comprising the Banská Bystrica, Žilina, Trenčín and Nitra regions. This cluster is not homogeneous in its mortality structure so the specificities and differences are clear. Especially the Banská Bystrica and Žilina regions are relatively close to G31 - Degeneration of nervous system. An interesting finding is the diagnosis of K70 - Alcoholic liver disease. In this case, three regions with moderate correspondence to this diagnosis can be identified. These are the Banská Bystrica, Trenčin, and Nitra regions. The Trnava is the only region with a slight relationship to F10 - Acute alcohol intoxication. The Trenčín and Nitra regions correspond to the diagnosis of G62 - Alcoholic polyneuropathy. The Košice region corresponds to the diagnosis of K73 - Chronic hepatitis and K74 - Fibrosis and cirrhosis of liver. From the overall assessment of the regions' relationships in alcohol-related mortality we find a breakdown into four groups of diseases according to ICD-10: I - Diseases of the circulatory system, $\mathrm{L}$ - Diseases of the digestive system, $\mathrm{G}$ - Diseases of the nervous system, and F - Mental and behavioural disorders. These findings are important for analysis of the structure, availability and efficiency of specialised healthcare facilities where diagnosis and treatment of these serious diagnoses is carried out. For example, F10 - Acute alcohol intoxication is linked to psychiatric examination or hospitalisation regardless of reasons for, and degree of, intoxication. According to experts, uncomplicated alcohol intoxication alone is not an indication for psychiatric examination and patients with severe intoxication should be hospitalised in an intensive care unit at an internal clinic (32). In Slovakia, this problem has for a long time been addressed by several ministries and municipalities. According to Janík and Vašečková (33) it is necessary to establish interdepartmental cooperation as well as to ensure sufficient personnel and technical equipment for the effective functioning of healthcare providers. Psychiatry as a discipline, according to these authors, should not substitute healthcare providers for repressive activities or take responsibility for longterm failure to address the issue. Further research findings are also important for setting up local prevention programmes in individual regions. If we look at the localisation of diagnoses belonging to the group of digestive system diseases, we find intervention in several regions. For this reason, it is necessary to focus on exploring the root causes of the emergence of these diseases which can result in liver transplantation. Liver transplantation is the last alternative and is only implemented after 6-month abstinence with presumption of long-term maintenance. If the abuse is stopped, the prognosis is more than favourable (34). In Slovakia, 30-50 people a year await liver transplantation (35). Liver transplantation is dependent on organ sampling in Slovakia. The sampling programme in Slovakia operates at approximately $50 \%$ and is provided by four centres: Bratislava, Martin, Banská Bystrica and Košice. Experts point out insufficient support from the Ministry of Health (36). Circulatory diseases such as I42 - Cardiomyopathy are dominant in the Prešov region which is sufficiently covered by a network of specialised cardiology clinics and has access to the specialised centre of the East Slovak Institute of Cardiovascular Diseases in Košice. Investigating the relationship of alcohol-related mortality and its spatial distribution is also of great importance in the process of building Integrated Health Care Centres, supported by the Ministry of Health of the Slovak Republic. This system prevails in many European countries alongside the complementary introduction of health system reforms which should result in an increase in the number of primary contact physicians, as well as site-specific specialists, increasing healthcare availability and improving patient management. The results of our analysis can help in assessing the demand for specialised health services in the catchment areas of Slovakia's regions and can help create the conditions for access to health care that regional disparities in health reduce.

\section{CONCLUSION}

For decades, Slovakia has been solving the problem of eliminating the effects of harmful alcohol use. The consequences of alcohol consumption from social, work-related, psychological and economic perspectives are extensive. To eliminate them it is important to streamline and intensify the systemic approach of relevant institutions to the issues addressed. Timely and good quality health care can improve the course of related diseases 
and reduce their health, social and economic consequences. An important role is played by the detailed mapping of risk areas as well as population groups and exploration of determinants supporting the development of alcohol dependence. Our findings can contribute as a key argument for stakeholders to improve the poor level of alcohol policy in the Slovak Republic, especially in terms of alcohol taxation and regulation of alcohol availability and advertisement. Public health interventions such as health promotion, raising awareness of alcohol-related harm and effective population-based prevention strategies should also be considered. The aim of our study was to investigate the relationship between alcohol-related mortality and individual regions of Slovakia, represented by regions (NUTS III level). To achieve these objectives, a correspondence analysis was chosen which allowed to exploration and evaluation of the spatial distribution of alcoholrelated mortality in individual regions of Slovakia. Results of the analysis enabled us to identify the regions which correspond to the mortality rate of selected diagnoses while we also revealed a cluster of several regions with their specificities as well as differences. These facts justify the need for specialised health care which is part of the process of building an Integrated Health Care Centre in Slovakia. It is a trend prevalent in many countries to improve the availability of health care. The analysis provides valuable insights for national and regional health policymakers in the process of preparing high-quality health regional plans, as well as retrospectively assessing the success of existing health policies and interventions in this area. A challenge for further research is to determine whether the changes in some diagnoses over the years are due to the changes in the prevalence of those diseases or due to higher/lower awareness of the diseases among doctors, or due to different coding policies.

\section{Acknowledgements}

Our thanks go out to the National Health Information Centre of the Slovak Republic along with the Statistical Office of the Slovak Republic for providing access to the central mortality database for the studied period as well as the other associated data. Our acknowledgments also belong to the Ministry of Health of the Slovak Republic for its cooperation in the creation of the new conceptions and methodologies and for its support of our research activities.

\section{Funding}

This paper was supported by the GCDPC, Grant No. A-86-19 and by the institutional support programme Progress No. Q06/LF1.

\section{Conflict of Interests}

None declared

\section{REFERENCES}

1. Bosakova L, Rosicova K, Filakovska Bobakova D, Rosic M, Dzurova D, Pikhart H, et al. Mortality in the Visegrad countries from the perspective of socioeconomic inequalities. Int J Public Health. 2019;64(3):365-76.

2. World Health Organization. Global Status report on Alcohol and Health. Geneva: WHO; 2011.

3. Mookerjee RP, Lackner C, Stauber R, Stadlbauer V, Deheragoda M, Aigelsreiter A, et al. The role of liver biopsy in the diagnosis and prognosis of patients with acute deterioration of alcoholic hepatitis. J Hepatol. 2011;55(5):1103-11.
4. Rehm J, Mathers C, Popova S, Thavorncharoensap M, Teerawattananon Y, Patra J. Global burden of disease and injury and economic cost attributable to alcohol use and alcohol-use disorders. Lancet. 2009;373(9682):222333.

5. GBD 2016 Alcohol and Drug Use Collaborators. The global burden of disease attributable to alcohol and drug use in 195 countries and territories, 1990-2016: a systematic analysis for the Global Burden of Disease Study 2016. Lancet Psychiatry. 2018;5(12):987-1012.

6. Zábranský T, Beláčková V, Štefunková M, Vopravil J, Langrová M. Social costs of the use of alcohol, tobacco, and illegal drugs in the Czech Republic, 2007. Prague: Department of Addictology, First Faculty of Medicine, Charles University in Prague and General Faculty Hospital in Prague; 2011. (In Czech.)

7. iHETA. Social costs of alcohol consumption in the Czech Republic [Internet]. iHETA; 2018 [cited 2019 Mar 13]. Available from: http:// www.iheta.org/p68-spolecenske-naklady-konzumace-alkoholu-v-cr. (In Czech.)

8. Nociar A. Age, gender and substance use in relation to violence at primary and secondary schools in Slovakia. In: 4th world conference Violence in school and public policies; 2008 Jun 23-25; Lisbon, Portugal. Lisbon: Faculty of Human Kinetics, Technical University of Lisbon; 2008.

9. Nociar A. European School Survey on Alcohol and Other Drugs (ESPAD) in Slovakia in 2015. Final Report. Bratislava: Research Institute of Child Psychology and Psychopathology; 2015. (In Slovak.)

10. Nociar A. Report from the TAD survey of primary school students, secondary school students and their teachers in 2014 Bratislava: Research Institute of Child Psychology and Psychopathology; 2014. (In Slovak.)

11. Madarasová Gecková A, Dankulicová Z, editors. National report on health and health-related behavior of 11,13 and 15 year old schoolchildren: based on a survey conducted in 2013/2014 as part of the international project "Health Behavior in School Aged Children" (HBSC). Košice: WHO Country Office in Slovakia; 2015 [cited 2017 Jul 10] Available from: http://www.infodrogy.sk/indexAction.cfm?module=Library\&acti on=GetFile \&DocumentID=1153. (In Slovak.)

12. Gavurová B, Koróny S, Barták M. The prevalence and perception of drinking among full-time Slovak University students in relation to socioeconomic determinants. Adiktologie. 2017;17(2):92-106. (In Slovak.)

13. Monitoring Center for Drugs and Drug Addiction (EMCDDA); Kastelová E, editor. The state of drug addiction and drug control in the Slovak republic in 2015. Equilibria; 2016.

14. Monnat SM. Factors associated with county-level differences in us drugrelated mortality rates. Am J Prev Med. 2018;54(5):611-9.

15. Rosicova K, Madarasova Geckova A, Rosic M, Speybroeck N, Groothoff JW, van Dijk JP. Socioeconomic factors, ethnicity and alcohol-related mortality in regions in Slovakia. What might a tree analysis add to our understanding? Health Place. 2011;17(3):701-9.

16. Barrios E, Sierra MS, Musetti C, Forman D. The burden of oesophageal cancer in Central and South America. Cancer Epidemiol. 2018;44 Suppl 1:S53-S61.

17. Saint Onge JM, Krueger PM. Health lifestyle behaviours among US adults. SSM-Popul Health. 2017;3:89-98.

18. Gennuso KP, Jovaag A, Catlin BB, Rodock M, Park H. Peer reviewed: assessment of factors contributing to health outcomes in the eight states of the Mississippi Delta Region. Prev Chronic Dis. 2016;13:E33. doi: http://dx.doi.org/10.5888/pcd13.150440

19. Renard F, Tafforeau J, Deboosere P. Mapping the cause-specific premature mortality reveals large between-districts disparity in Belgium, 2003-2009. Arch Public Health. 2015;73(1):13. doi 10.1186/s13690-015-0060-5.

20. Jeon YJ, Kim CR, Park JS, Choi KH, Kang MJ, Park SG, et al. Health inequalities in hypertension and diabetes management among the poor in urban areas: a population survey analysis in south Korea. BMC Public Health. 2016;16:492. doi: 10.1186/s12889-016-3169-8.

21. Beard E, Brown J, West R, Angus C, Kaner E, Michie S. Healthier central England or North-South divide? Analysis of national survey data on smoking and high-risk drinking. BMJ Open. 2017;7(3):e014210. doi:10.1136/bmjopen-2016-014210.

22. OECD. Alcohol consumption [Internet]. OECD; 2019 [cited 2019 Sep 10]. Available from: https://data.oecd.org/healthrisk/alcohol-consumption. htm.

23. Popova S, Rehm J, Patra J, Zatonski W. Comparing alcohol consumption in central and eastern Europe to other European countries. Alcohol Alcohol. 2007;42(5):465-73.

24. World Health Organization. Global status report on alcohol and health 2018. Geneva: WHO; 2018. 
25. European Monitoring Centre for Drugs and Drug Addiction. European drug report 2019: trends and developments. Luxembourg: Publications Office of the European Union; 2019.

26. Formnek T, Kagström A, Cermakova P, Csémy L, Mladá K, Winkle P. Prevalence of mental disorders and associated disability: results from the cross-sectional CZEch mental health Study (CZEMS). Eur Psychiatry. 2019;60:1-6.

27. Kagstrom A, Alexova A, Tuskova E, Csajbok Z, Schomerus G, Formanek $\mathrm{T}$, et al. The treatment gap for mental disorders and associated factors in the Czech Republic. Eur Psychiatry. 2019;59:37-43.

28. Janssen MM1, Mathijssen JJ, van Bon-Martens MJ, van Oers HA, Garretsen HF. Effectiveness of alcohol prevention interventions based on the principles of social marketing: a systematic review. Subst Abuse Treat Prev Policy. 2013 Jun 1;8:18. doi: 10.1186/1747-597X-8-18.

29. Čablová L, Miovský M. Risk and protective factors in the family that predict alcohol use of children and adolescents. Cesk Psychol. 2013;57(3):255-70. (In Czech.)

30. Benzécri JP. L'Analyse des Données. Volume II.: L'Analyse des Correspondances. Paris: Dunod; 1973.

31. Hirschfeld HO. A connection between correlation and contingency. Proc Camb Philos Soc. 1935;31(4):520-4.
32. Novotný V, Janík P. Does psychiatry substitute for drunk tank?. Alkohol Drog Záv (Protialkohol Obz). 2010;45(1):107-12. (In Czech.)

33. Janík P, Vašečková B. Urgent hospitalizations due to alcohol intoxication. Alkohol Drog Záv (Protialkohol Obz). 2012;47(5):285-92. (In Czech.)

34. Szantova M. Alcoholic liver disease. Alkohol Drog Záv (Protialkohol Obz). 2013;48(1):25-35. (In Czech.)

35. FNsP F. D. Roosevelta. The first liver transplantation in Slovakia was performed in Banská Bystrica 20 years ago [Internet]. BBonline; 2017 [cited 2019 Mar 3]. Available from: https://bbonline.sk/pred-dvadsiatimirokmi-prebehla-v-bystrici-prva-transplantacia-pecene-na-slovensku/. (In Slovak.)

36. Miso P, Maslejová V. We're losing the fight for the liver. Why do we do few transplants? [Internet]. iZdravie; 2014 [cited 2019 Mar 3]. Available from: https:/www.pluska.sk/izdravie/liecba/boj-pecen-prehravamepreco-robime-malo-transplantacii.html. (In Slovak.)

Received March 22, 2019 Accepted in revised form September 22, 2019 